\title{
Impact of light conditions on reading ability following multifocal pseudophakic corrections
}

This article was published in the following Dove Press journal:

Clinical Ophthalmology

\author{
Georgios Labiris \\ Panagiota Ntonti \\ Eirini-Kanella \\ Panagiotopoulou \\ Aristeidis Konstantinidis \\ Maria Gkika \\ Doukas Dardabounis \\ Irfan Perente \\ Haris Sideroudi \\ Department of Ophthalmology, \\ University Hospital of \\ Alexandroupolis, Alexandroupolis, \\ Greece
}

\begin{abstract}
Purpose: To examine the impact of light intensity and temperature on reading performance following bilateral pseudophakic multifocal presbyopic correction.

Patients and methods: This is a prospective clinic-based trial conducted at the Department of Ophthalmology in the University Hospital of Alexandroupolis, Greece. Three groups of patients were formed (G1: patients with bilateral bifocal implantation, G2: patients with bilateral trifocal implantation, and control group: patients with bilateral pseudophakic monofocal implantation). Reading ability was quantified with the Greek version of MNREAD chart with minimal reading speed at 80 words/min for the following light intensities (25, 50, and 75 Foot-Candles [FC]) and temperatures $(3,000,4,000$, and 6,000 K). Preferred light conditions for reading were assessed, as well. ClinicalTrials.gov Identifier: NCT03226561.
\end{abstract}

Results: Control group demonstrated significantly lower reading ability at all light combinations with maximal ability at $75 \mathrm{FC}$ and $6,000 \mathrm{~K}(0.58 \pm 0.18 \log \mathrm{MAR})$. Bifocal group presented a light-dependent reading ability that ranged from $0.45 \pm 0.08 \log \mathrm{MAR}(25 \mathrm{FC}$ and $3,000 \mathrm{~K})$ to $0.40 \pm 0.11 \log$ MAR ( $75 \mathrm{FC}$ and 4,000 or $6,000 \mathrm{~K}$ ). Trifocal participants presented the best reading ability that was light intensity-independent; however, their performance was reduced at $6,000 \mathrm{~K}$. G1 and G2 preferred primarily intermediate light temperature, while control participants preferred cold light temperature.

Conclusion: Multifocal pseudophakic corrections improve reading ability; however, they present variable efficacy according to the light conditions.

Keywords: presbyopia, light intensity, Kelvin, Foot-Candles, trifocal, bifocal

\section{Introduction}

Presbyopia is an age-related visual disorder that results in a progressive impairment of near-focusing ability. It is common for emmetropic populations above 40 years old; eventually almost everyone will demonstrate a variable amount of near-vision deterioration. ${ }^{1}$ Presbyopia symptoms include blurry vision when targeting near objects and fatigue when reading at a short distance, especially in suboptimal lighting conditions. ${ }^{2,3}$ Taking into account the constantly increasing life-expectancy, conservative estimates suggest that by $2050 \sim 1.8$ billion people will experience presbyopia-associated symptoms. ${ }^{4}$ Moreover, since working and social norms have been modified heavily with the usage of computers, tablets, and smart phones, presbyopia imposes significant limitations to the patient's productivity and reduces quality of life to a great extent. 5,6

\section{Presbyopia - theories}

The term presbyopia refers to the reduction of the accommodation capacity of the eye because of the aging process. Few pathomechanisms have been described that contribute to this phenomenon, but there is no distinctive cause. Phakic theories suggest
Correspondence: Georgios Labiris Department of Ophthalmology, University Hospital of Alexandroupolis, 68100 Dragana, Alexandroupolis, Greece Tel +306977455027

Fax +30255 1030405 Email labiris@usa.net 
that changes in the elasticity of the lens capsule can possibly hinder the flattening of the crystalline lens or the thickening of the lens itself along with the reduction of the elasticity of the lens fibers. ${ }^{7,8}$

Nonphakic theories suggest that the continuous growth of the eye alters the correlation between the cilliary body and the crystalline lens modifying the tension attributed by the cilliary body. This is caused due to the replacement of the muscle fibers of the cilliary body with connective tissue due to aging. ${ }^{9}$

\section{Multifocal lenses}

Multifocal intraocular lenses (mIOLs) are constantly gaining popularity as a reliable surgical option in presbyopia correction. ${ }^{10-13}$ mIOLs are manufactured based on the fundamental principles of light diffraction and refraction. Diffractive mIOLs have the ability to concentrate on light rays simultaneously at multiple points across the propagation axis. This becomes possible because of their unique design, which consists of a repeating pattern that can be formulated at the surface of an optical medium that resembles a sequence of concentrate annular zones, with each zone narrowing down from the center to the periphery of the lens. For example, there might be 20-30 zones between the center and the edge of a lens whose surface profile is typically a smooth varying function such as an arch or a parabola. At the outer periphery of each zone, there is a step in the vertical surface profile that has a height of $0.5-3 \mu$. This structure results in a surface that acts as a circularly symmetric diffraction unit that can disperse light into multiple diffraction orders.

The percentage of light energy transmitted into each one of the diffractive orders comprising the diffraction pattern at a focal plane is referred to as diffraction efficiency. If the zones have equal surface areas and are symmetric they have the ability to focus the light rays transmitted from each one of the refractive orders onto the optical axis of the lens, with each diffraction order having its own foci. Therefore, the lens acts like a multifocal lens that has many discrete foci. For example, bifocal lenses provide simultaneously two focused retinal images in two different distances, as well as two corresponding nonfocused images. The human visual system can adapt by selecting between the different retinal images enabling multifocal vision. ${ }^{14}$

\section{Intensity and temperature of lighting}

The unit of Foot-Candles (FC, $1 \mathrm{~m} / \mathrm{ft}^{2}, \mathrm{ft}-\mathrm{c}$ ) quantifies the intensity of the light from various light sources. It is defined as the brightness attributed to a surface by a light source of 1 candela intensity, that is at one foot distance from the surface. It is equivalent to 10 lux in SI.

Apart from the light intensity, equally important is the light temperature or the light color temperature. It is defined as the temperature of an ideal black body that emits radiation with a similar color as the referred light source and is measured in Kelvin (K). Practically, color temperatures above 5,000 K are considered cold colors, such as ice white, whereas color temperatures from 2,700 to 3,000 $\mathrm{K}$ are considered warm colors, like yellow, white, or red. ${ }^{15}$ The control of color temperature has many practical applications as in digital photography and the construction of electronic screens, but also at the configuration of indoor environments. For example, a "warm" color (color with low color temperature) is best used in relaxation areas, while a "cooler" color (higher color temperature) is preferable in working spaces, as it can promote concentration.

\section{Near visual acuity charts}

Reading is firmly associated with life quality. Therefore, the evaluation of reading ability plays a significant role in the eye examination. For the assessment of near visual capacity, a great diversity of near visual acuity charts has been developed. Among all available near visual acuity charts, the MNREAD chart seems to present considerable benefits. Among them, the possibility for measurement of near visual acuity on a $\log$ MAR scale. ${ }^{16}$ MNREAD has been developed in 1995 by the Minnesota Low Vision Laboratory. It consists of short sentences with print size decreasing by $0.1 \log$ MAR steps from a maximum of $1.3 \log$ MAR (corresponding to Snellen $20 / 400$ or $6 / 120$ ) to $-0.5 \operatorname{logMAR}$ (corresponding to $20 / 6$ or 6/1.9) when viewed from a reading distance of $40 \mathrm{~cm}$.

Within this context, primary objective of this study was to determine the impact of light intensity and temperature on the reading performance in patients that underwent bilateral pseudophakic multifocal corrections. Within the objectives of the study was to identify potential patterns that could serve as the scientific background for introduction of lighting guidelines for these patients.

\section{Patients and methods Setting}

This is a prospective, nonrandomized controlled study. Protocol adhered to the Declaration of Helsinki, while written informed consent was provided by all participants. The scientific board of Democritus University of Thrace approved the study protocol. The study was conducted at 
the Department of Ophthalmology in the University Hospital of Alexandroupolis, Greece, between October 2017 and April 2018.

\section{Participants}

Patients were enrolled in a consecutive-if-eligible basis and populated three distinct groups for the purposes of this study. 1) G1 group: patients that underwent bilateral presbyopic correction with implantation of a bifocal hybrid intraocular lens ReSTOR (add +2.50) (Alcon Laboratories, Inc., Fort Worth, TX, USA). 2) G2 group: patients that underwent bilateral presbyopic correction with the use of a trifocal diffractive intraocular lens PanOptix (Alcon Research). 3) CG group (control group): patients of similar age that underwent bilateral pseudophakic monofocal correction. The monofocal intraocular lens used in the CG group was AcrySof IQ SF60WF (Alcon Research). Inclusion criteria for all groups included diagnosis of senile cataract either stage 2 or 3 of the Lens Opacities Classification System III (LOCS-3) grading scale; while exclusion criteria for all groups included: astigmatism $>1.00$ diopters, glaucoma, former incisional eye surgery, corneal or fundus disease, diabetes mellitus, autoimmune diseases, neurological or psychiatric diseases, posterior capsule rupture, or lens misalignment. To minimize potential dysphotopic phenomena in pseudophakic multifocal corrections, all G1 and G2 participants had to present pupil centroid shift (shift of the pupil center in the transition from the dilated pupil in low mesopic conditions to a constricted pupil in photopic conditions) below $0.4 \mathrm{~mm}$ and a small-to-average pupil diameter in low mesopic conditions $(<5 \mathrm{~mm}) .{ }^{17}$

Centroid shift and pupil behavior was evaluated using the dynamic pupil measurement module Wavelight Topolyzer Vario (Alcon Research). The pupillometries were performed in a dark room of illumination $\leq 1$ lux. The head of patients was covered with a thick black cloth in order the lighting conditions to reach 0.4 lux. The Topolyzer Vario first made measurements with the Placido disc's light off(low mesopic lighting conditions $-0.4 \mathrm{lux}$ ), then with the light on (photopic conditions - 120 lux). Illuminance values were obtained using a handheld light meter (Topwor-US, Sunche HS1010, Shanghai, China). All measurements were performed by the same operator (EKP).

\section{Surgical technique}

All surgical procedures were performed by the same surgeon (GL) in the same consistent way, as described before, using the Alcon Infinity VisionSystem platform ( $80 \%$ amplitude, $350 \mathrm{mmHg}$ vacuum limit, and $40 \mathrm{~mL} / \mathrm{min}$ aspiration rate), ${ }^{18}$ and the Verion Digital marker System. Pupil dilation was performed with tropicamide $0.5 \%$ (Tropixal, Demo, Greece). Periorbital skin, eyelids, and the conjunctival sac were prepared with a solution of iodine povidone (Betadine). Patients received topical anesthesia with hydrochlorine propacaine of $0.5 \%$ drops. Main incision ( $2.2 \mathrm{~mm}$ self-sealing upper temporal or upper nasal) and two contralateral stab incisions were guided by Verion System in order to minimize surgically induced astigmatism. 3\% Sodium hyaluronate, 4\% chondroitin sulfate (Viscoat, Alcon, Athens, Greece), and 1\% sodium hyaluronate (Hiluron, Vadodara, Athens, Greece) Ophthalmic Viscosurgical Devices (OVDs) were used at the different stages of operation. ${ }^{19}$ Capsulorhexis was guided by Verion, set at $4.5 \mathrm{~mm}$ with the center at the visual axis.

\section{Intraocular lens characteristics}

The Restor IOL that was used in G1 group offers a refractive power of +2.50 diopters for near vision. It is a bifocal yellow intraocular lens constructed by an acrylate/methacrylate copolymer, with a $6 \mathrm{~mm}$ body diameter and a $13 \mathrm{~mm}$ total diameter including haptics. It has a UV, as well as a blue radiation filter. It has the ability to enhance the visual capacity at $53 \mathrm{~mm}$ for near targets and $4 \mathrm{~m}$ for distant ones. At its anterior aspect there is an apodized diffractive aspherical surface, with a central refractive zone (hybrid lens). ${ }^{20,21}$

The Panoptix IOL that was used in G2 group is a trifocal, yellow intraocular lens of an acrylate/methacrylate copolymer. It has UV and blue radiation filters. Besides near distance ( +3.20 diopters) and distant vision, it has the ability to enhance intermediate distance vision at $60 \mathrm{~cm}$ $(+2.20$ diopters $)$. It is a nonapodized, diffractive intraocular lens that is supposed to provide optimal outcomes regardless of pupil size. ${ }^{20,21}$

\section{Data collection}

For the purposes of the survey, a simulation room with userdefined lighting conditions was developed at the Democritus University of Thrace. The simulation room allowed the assessment of bilateral near vision capacity at task light temperatures of 3,000, 4,000, and 6,000 $\mathrm{K}$ and at light intensities of 25, 50, and 75 FC. Therefore, nine combinations of light conditions were evaluated. Bilateral noncorrected visual capacity was assessed with the Greek version of the MNREAD acuity chart (MNREAD-GR) validated for Greek populations. ${ }^{22}$ The noncorrected reading performance was evaluated at a reading distance of $40 \mathrm{~cm}$ at a minimal reading speed of 80 words per minute. Apart from the objective assessment of the reading capacity, each participant 
had to declare the optimal light combination that was the most comfortable according to his/her subjective opinion.

\section{Statistical analyses}

The normality of measured data was evaluated by ShaphiroWilk's test. Normal distribution data were assessed by Student's $t$-test or ANOVA. Nonparametric data were assessed with Mann-Whitney $U$-test. Multiple linear regression analysis was attempted in order to identify the primary determinant (either light intensity or light temperature) of the reading ability. Values at the $P<0.05$ were considered as statistically significant. All statistical analyses were performed with the Medcalc version 9.6.2.0 (Medcalc Software, Mariakerke, Belgium).

\section{Results}

Patient demographics are presented in Table 1. A total of 75 people ( $n=25$ patients in each group) participated in the study, with an average age of 63 years that populated the three groups. Nonsignificant differences were detected in age (G1: 62.34 \pm 14.12 years, G2: $64.21 \pm 11.19$ years, CG: $61.43 \pm 12.47$ years $[P=0.23])$, spherical equivalent $(\mathrm{G} 1:-0.11 \pm 0.48 \mathrm{D}, \mathrm{G} 2$ : $0.19 \pm 0.32 \mathrm{D}, \mathrm{CG}:-0.23 \pm 0.68 \mathrm{D}[P=0.14])$, low mesopic and photopic pupil diameters $(P=0.17$ and $P=0.21$, respectively), and pupil center shift (G1: $0.10 \pm 0.03 \mathrm{~mm}, \mathrm{G} 2$ : $0.13 \pm 0.05 \mathrm{~mm}, \mathrm{CG}: 0.12 \pm 0.06 \mathrm{~mm}[P=0.19])$.

Reading ability for all groups at different light temperatures and intensities is presented in Table $2 \mathrm{a}(3,000 \mathrm{~K}), 2 \mathrm{~b}$ $(4,000 \mathrm{~K})$, and $2 \mathrm{c}(6,000 \mathrm{~K}) . \mathrm{G} 2$ patients performed better than the rest of the study participants at all light intensities (all $P<0.01$ ) followed by G1 patients. Significant worse reading ability at all light conditions was detected in $C G$ group. Regarding light intensity, G1 patients presented significantly better reading ability at $75 \mathrm{FC}$ for temperatures at 3,000 and $4,000 \mathrm{~K}(P=0.04$ and $P=0.03$, respectively). Light intensity had a no significant impact on G2 group's reading performance (all $P>0.05$ ), while CG participants could definitely perform better in colder and intense light conditions (CG: 0.58 $\pm 0.18 \log \mathrm{MAR}$ at $75 \mathrm{FC}$ and $6,000 \mathrm{~K}$ ). However, G2 participants performed better in intermediate light temperature, reaching their optimal reading ability at $75 \mathrm{FC}$ and 4,000 K (0.22 $\pm 0.04 \log$ MAR). Multiple regression analysis for each group identified the primary determinant of the dependent variable reading ability. For G1 and CG participants regression model $\left(R^{2}=0.896\right.$ and 0.924 , respectively) identified light intensity as the primary determinant ( $r=-0.787,-0.885)$, while for $\mathrm{G} 2$ participants, regression model $\left(R^{2}=0.649\right)$ identified light temperature as the primary determinant $(r=0.802)$.

Reading ability radar charts for different light conditions are presented in Figures 1-3. Figure 1 demonstrates suboptimal light conditions for reading (ie, $25 \mathrm{FC}$ at 3,000 K) in which all study participants demonstrated their worst reading capacity, Figure 2 at $75 \mathrm{FC}$ and 4,000 K (optimal conditions for $\mathrm{G} 2$ participants), and Figure 3 at $75 \mathrm{FC}$ and $6,000 \mathrm{~K}$ (optimal conditions for G1 and CG participants). In all three radar charts, $\mathrm{G} 2$ participants were closer to 0 (infinite reading capacity) followed by G1 and CG patients, respectively.

On the other hand, subjective preference for lighting conditions during reading is presented in Table 3. All CG participants preferred cold, intense light that provided improved reading capacity; $68 \%$ (17/25) of G1 and 76\% (19/25) of G2 participants preferred intermediate light temperature. Interestingly enough, $50 \%$ of G2 patients preferred low $(2 / 25)$ or intermediate (13/25) light intensity.

\section{Discussion}

It is a truism that presbyopia's impact on Health care Systems is significant; ${ }^{4}$ primarily due to the reason that the vast majority of people will experience a variable decrease of their near-vision capacity, and, secondarily because it usually onsets at the productivity peak of the working life. ${ }^{23}$

Table I Study participants

\begin{tabular}{|l|l|l|l|l|}
\hline Parameters & GI & G2 & CG \\
\hline N & 25 & 25 & 25 & NA \\
\hline Age (years) & $62.34 \pm 14.12$ & $64.21 \pm 11.19$ & $61.43 \pm 12.47$ & 0.23 \\
\hline Spherical equivalent (D) & $-0.1 I \pm 0.48$ & $0.19 \pm 0.32$ & $-0.23 \pm 0.68$ & 0.14 \\
\hline Photopic pupil diameter (mm) & $2.5 I \pm 0.4 I$ & $2.45 \pm 0.62$ & $2.53 \pm 0.39$ & 0.21 \\
\hline Low mesopic pupil diameter (mm) & $4.24 \pm 0.24$ & $4.45 \pm 0.53$ & $0.13 \pm 0.05$ & $0.12 \pm 0.06$ \\
\hline Pupil center shift (mm) & $0.10 \pm 0.03$ & 0.17 & 0.19 \\
\hline
\end{tabular}

Notes: Photopic lighting conditions: 120 lux; low mesopic lighting conditions: 0.4 lux.

Abbreviations: CG, control group; D, diopters; GI, Restor group; G2, Panoptix group; NA, non applicable. 
Table 2 Reading ability at different light conditions (logMAR)

\begin{tabular}{|c|c|c|c|c|}
\hline Table 2a & \multicolumn{3}{|c|}{ Temperature $3,000 \mathrm{~K}$} & \multirow[t]{2}{*}{$P$-value } \\
\hline Intensity (FC) & G I & G2 & CG & \\
\hline 25 & $0.45 \pm 0.08$ & $0.26 \pm 0.04$ & $0.65 \pm 0.16$ & $<0.01$ \\
\hline 50 & $0.43 \pm 0.10$ & $0.24 \pm 0.06$ & $0.62 \pm 0.16$ & $<0.01$ \\
\hline 75 & $0.4 I \pm 0.09$ & $0.24 \pm 0.04$ & $0.61 \pm 0.16$ & $<0.01$ \\
\hline$P$-value & 0.04 & 0.15 & 0.03 & NA \\
\hline Table 2b & \multicolumn{4}{|c|}{ Temperature $4,000 \mathrm{~K}$} \\
\hline 25 & $0.44 \pm 0.07$ & $0.26 \pm 0.06$ & $0.64 \pm 0.17$ & $<0.01$ \\
\hline 50 & $0.42 \pm 0.08$ & $0.24 \pm 0.08$ & $0.61 \pm 0.18$ & $<0.01$ \\
\hline 75 & $0.40 \pm 0.11$ & $0.22 \pm 0.04$ & $0.60 \pm 0.19$ & $<0.01$ \\
\hline$P$-value & 0.03 & 0.17 & 0.01 & NA \\
\hline Table 2c & \multicolumn{4}{|c|}{ Temperature $6,000 \mathrm{~K}$} \\
\hline 25 & $0.42 \pm 0.15$ & $0.30 \pm 0.04$ & $0.63 \pm 0.18$ & $<0.01$ \\
\hline 50 & $0.40 \pm 0.15$ & $0.28 \pm 0.06$ & $0.61 \pm 0.17$ & $<0.01$ \\
\hline 75 & $0.40 \pm 0.11$ & $0.30 \pm 0.06$ & $0.58 \pm 0.18$ & $<0.01$ \\
\hline$P$-value & 0.06 & 0.31 & 0.03 & NA \\
\hline
\end{tabular}

Note: Minimal reading speed: 80 words/minute.

Abbreviations: CG, control group; GI, Restor group; G2, Panoptix group; NA, no data available; FC, foot-candles; K, kelvins.

Spectacles have traditionally been used as the primary conventional correction method for presbyopia; however, their use is associated with significant reduction in the quality of life. ${ }^{6}$ In fact, the psychological impact of presbyopia spectacles forces many people to prefer quitting activities that require near-vision capacity in order to avoid using spectacles.

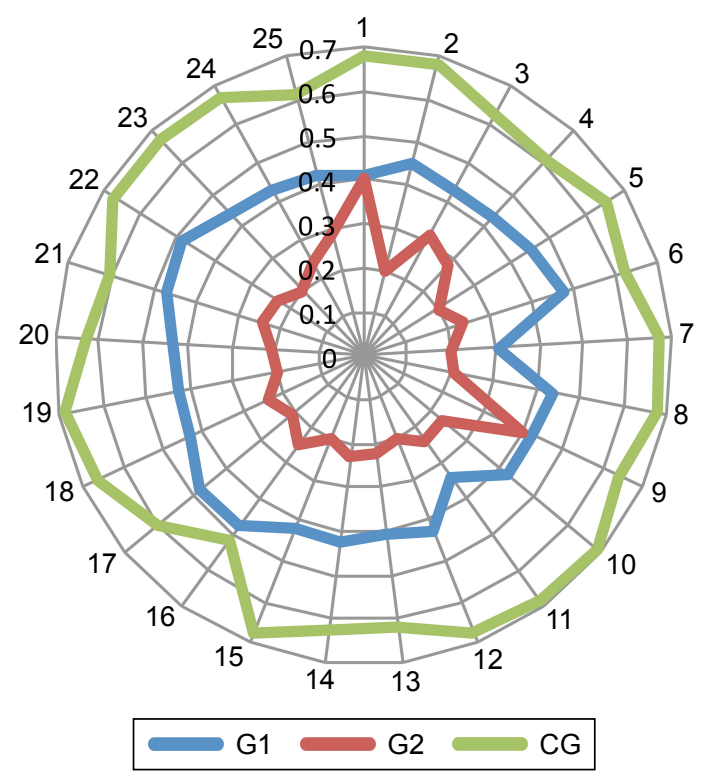

Figure I Reading ability (3,000 K, 25 FC).

Abbreviations: CG, control group; FC, Foot-Candles; GI, Restor group; G2, Panoptix group; K, kelvins.

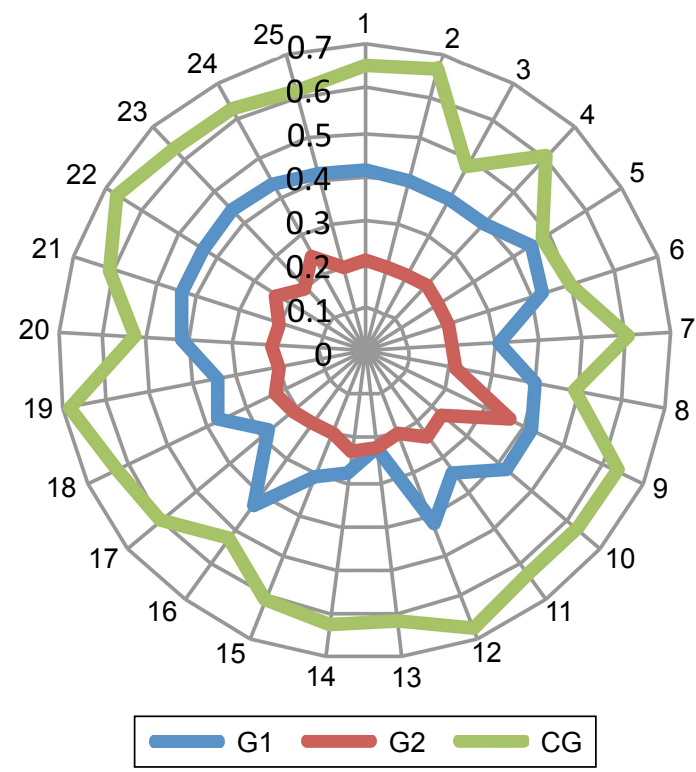

Figure 2 Reading ability $(4,000 \mathrm{~K}, 75 \mathrm{FC})$.

Abbreviations: CG, control group; FC, Foot-Candles; GI, Restor group; G2, Panoptix group; K, kelvins.

Among the most prevalent activities that require nearvision capacity is reading. Moreover, reading ability is among the first to gradually deteriorate, with presbyopia; therefore, among the fundamental parameters to be evaluated in relevant studies. ${ }^{24-27}$ However, clinical experience suggests that reading ability, and generally visual performance depends heavily on light conditions. ${ }^{28}$ Indeed, lighting is essential to our perception of the surroundings, whether it is natural

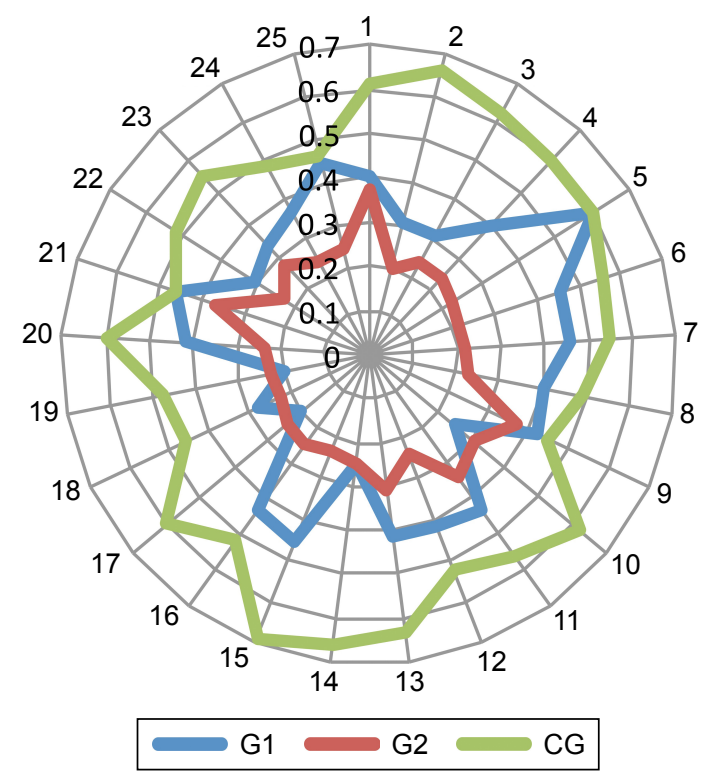

Figure 3 Reading ability (6,000 K, 75 FC).

Abbreviations: CG, control group; FC, Foot-Candles; GI, Restor group; G2, Panoptix group; K, kelvins. 
Table 3 Subjective preference for lighting conditions during reading (number of subjects)

\begin{tabular}{|c|c|c|c|c|c|c|c|c|c|}
\hline Temperature & $3,000 \mathrm{~K}$ & & & $4,000 \mathrm{~K}$ & & & 6,000 & & \\
\hline Intensity & $25 \mathrm{FC}$ & $50 \mathrm{FC}$ & $75 \mathrm{FC}$ & $25 \mathrm{FC}$ & $50 \mathrm{FC}$ & $75 \mathrm{FC}$ & $25 \mathrm{FC}$ & $50 \mathrm{FC}$ & $75 \mathrm{FC}$ \\
\hline GI & 0 & 0 & 0 & 0 & 2 & 15 & 0 & I & 7 \\
\hline G2 & 0 & 0 & 0 & 2 & 8 & 7 & 0 & 4 & 4 \\
\hline $\mathrm{CG}$ & 0 & 0 & 0 & 0 & 0 & 0 & 0 & 2 & 23 \\
\hline
\end{tabular}

Abbreviations: CG, control group; FC, Foot-Candles; GI, Restor group; G2, Panoptix group; K, kelvins.

or artificial, both in outdoor and indoor spaces. This refers to recreational activities, but more importantly at working spaces and educational facilities. Therefore, there was a need to enact specific guidelines regarding the best lighting conditions for every room and occasion. The IES (Illuminating Engineering Society) issued a detailed manual for these purposes for working, educational and private facilities. ${ }^{29}$ However, no lighting guidelines have been issued for monofocal or multifocal pseudophakic patients.

Within this context, primary objective of this study was to evaluate the reading ability of pseudophakic patients with bilateral monofocal, bifocal, or trifocal intraocular lenses at different light conditions. Among the objectives of the study was to reveal potential differences that could serve as the scientific background for the development of lighting recommendations to these groups of patients. It should be mentioned that since our study was targeting "spectaclesfree" patients, our CG were not corrected by spectacles, since, as already mentioned, these patients are most likely to experience reduced quality of life due to presbyopia. ${ }^{18}$ Therefore, these patients by default have an obvious disadvantage compared to patients with bi/trifocal IOLs when it comes to near vision.

The outcomes of our study are outlined below:

1. Monofocal corrections who do not use spectacles present poor reading ability. This reading ability is improved significantly in cold, intense lighting (75 FC, 6,000 K). However, as presented in Figures 1-3, task lighting conditions cannot substitute any correction device (ie, contact lenses), and these patients are most likely to quit reading, unless use spectacles.

2. Bifocal corrections with $2.5 \mathrm{D}$ add-on provide variable reading ability, according to the light conditions. Reading performance varies from average in warm, dim lighting $(25 \mathrm{FC} / 3,000 \mathrm{~K})$ to almost flawless in cold, intense lighting $(75 \mathrm{FC} / 6,000 \mathrm{~K})$.

3. Trifocal corrections provide superior reading capacity in comparison to the rest of the groups. This ability was light intensity-independent for temperatures at 3,000 and $4,000 \mathrm{~K}$. A peculiar finding in our patients was a nonsignificant reduction in reading performance at the temperature of $6,000 \mathrm{~K}$ that was independent of the light intensity. This finding was confirmed by the regression analysis, as well, which identified light temperature as the primary determinant of reading ability. Moreover, the majority of our trifocal patient (68\%) explicitly declared that the cold light was rather uncomfortable for reading, and preferred warmer conditions. $56 \%$ of trifocal patients preferred the intermediate light intensity of $50 \mathrm{FC}$ and not the $75 \mathrm{FC}$. We cannot fully explain the observed reduced performance in cold light conditions for the Panoptix lens. Since the Restor $+2.5 \mathrm{D}$ has the exact same filters we can assume a potential suboptimal function in the redistribution mechanism of the light (Enlighten technology) in cold light conditions. However, this observation must be confirmed in laboratory settings.

Nevertheless, potential differences in the behavior of the lenses under different light conditions should be further explored in order to identify the optimal suggested lighting. Unfortunately, there are many varieties in the published literature regarding light conditions, ${ }^{24,25}$ or reading tools ${ }^{24-27}$ when assessing reading ability. On the other hand, no published report could be retrieved that evaluated the impact of light temperature following pseudophakic multifocal corrections, despite the fact that it is a well-recognized parameter in the light industry with significant impact on physical and mental function. ${ }^{30}$ Within this context any direct comparison with published reports should be treated with caution. However, there is an almost universal methodological consensus regarding the minimal reading speed of $80 \mathrm{words} / \mathrm{min}$ that was used in this study. ${ }^{31}$

The superior outcomes in reading ability of the trifocal lens do not necessarily mean that it substitutes the bifocal one. Restor 2.5 D and Panoptix are two completely different lenses in terms of design; therefore, they target different groups of patients. The central refractive zone (ActiveFocus technology) of Restor 2.5 D is supposed to provide optimal distant visual capacity (for a multifocal lens). ${ }^{32}$ Under proper light conditions Restor 2.5 D patients will not need spectacles for the majority of their near vision tasks, as well. 
Certain limitations of the study should be noted prior to the interpretation of our results. 1) No randomization was possible among the multifocal groups. It is known that multifocal IOL selection, further to the clinical criteria, depends primarily on lifestyle, working and personal characteristics. 2) As in all cases that receive multifocal corrections in our Hospital, our patients were carefully selected in terms of low mesopic pupil dilation and centroid shift. Patients with less strict enrollment criteria might present different results and allow potential correlations with pupil behavior.

Further studies with larger cohorts of patients are necessary to confirm our outcomes. Moreover, further to reading, evaluation of other activities of daily living in predefined lightings will help us to identify the optimal light conditions for working or home environments that will improve multifocal IOL performance.

\section{Conclusion}

Near-vision capacity depends heavily on light conditions. Reading ability is a fundamental, daily task of the modern western patient. Trifocal patients will present superior reading ability; however, the prevalent intense, cold lighting of modern working settings does not contribute to superior near-vision capacity. Therefore, lighting recommendations for these patients should be revised. Bifocal patients present variable, light dependent, and reading ability. Bifocal patients will benefit from intense, cold lighting, and in the majority of their near-vision tasks will be spectacles-free.

\section{Author contributions}

GL conceived and designed the study, performed the operations, wrote the main manuscript, and supervised the study. PN involved in data collection/data analysis/ interpretation of data. EKP involved in data collection and drafting the manuscript. $\mathrm{AK}$ and $\mathrm{MG}$ involved in data acquisition. DD and IP involved in data analysis/interpretation of data. HS contributed to the conception and the design of the work, involved in data analysis/interpretation of data/ statistical analysis and supervised the paper. All authors contributed to data analysis, drafting or revising the article, gave final approval of the version to be published, and agree to be accountable for all aspects of the work.

\section{Data sharing statement}

The authors are willing to share the individual de identified participant data including written consent forms and study information leaflets for at least 1 year following the publication of our manuscript, acceptable in print form. Please note that all relevant data are in Greek language.

\section{Disclosure}

The authors report no conflicts of interest in this work.

\section{References}

1. Lu Q, Congdon N, He X, Murthy GVS, Yang A, He W. Quality of life and near vision impairment due to functional presbyopia among rural Chinese adults. Invest Ophthalmol Vis Sci. 2011;52(7): 4118-4123.

2. Alió JL, Plaza-Puche AB, Piñero DP, et al. Optical analysis, reading performance, and quality-of-life evaluation after implantation of a diffractive multifocal intraocular lens. J Cataract Refract Surg. 2011; 37(1):27-37.

3. Labiris G, Ntonti P, Patsiamanidi M, Sideroudi H, Georgantzoglou K, Kozobolis VP. Evaluation of activities of daily living following pseudophakic presbyopic correction. Eye Vis (Lond). 2017;4:2.

4. Frick KD, Joy SM, Wilson DA, Naidoo KS, Holden BA. The global burden of potential productivity loss from uncorrected presbyopia. Ophthalmology. 2015;122(8):1706-1710.

5. Chou KL. Combined effect of vision and hearing impairment on depression in older adults: evidence from the English Longitudinal Study of Ageing. J Affect Disord. 2008;106(1-2):191-196.

6. Luo BP, Brown GC, Luo SC, Brown MM. The quality of life associated with presbyopia. Am J Ophthalmol. 2008;145(4):618-622.

7. Fisher RF. Presbyopia and the changes with age in the human crystalline lens. J Physiol. 1973;228(3):765-779.

8. Glasser A. On modeling the causes of presbyopia. Vision Res. 2001; 41(24):3083-3087.

9. Pardue MT, Sivak JG. Age-related changes in human ciliary muscle. Optom Vis Sci. 2000;77(4):204-210.

10. Versteeg FF. Multifocal IOLs for presbyopia. J Cataract Refract Surg. 2005;31(7):1266.

11. Steinert RF. Visual outcomes with multifocal intraocular lenses. Curr Opin Ophthalmol. 2000;11(1):12-21.

12. Gil-Cazorla R, Shah S, Naroo SA. A review of the surgical options for the correction of presbyopia. Br J Ophthalmol. 2016;100(1):62-70.

13. Labiris G, Patsiamanidi M, Giarmoukakis A, Kozobolis VP. Patient satisfaction and spectacle independence with the iSert multifocal lens. Eur J Ophthalmol. 2015;25(2):e1-e2.

14. Weeber HA, Meijer ST, Piers PA. Extending the range of vision using diffractive intraocular lens technology. J Cataract Refract Surg. 2015; 41(12):2746-2754.

15. Rüdiger Paschotta. Encyclopedia of Laser Physics and Technology. Wiley-VCH; Berlin; 2008.

16. Calabrèse A, Cheong AM, Cheung SH, et al. Baseline MNREAD Measures for Normally Sighted Subjects From Childhood to Old Age. Invest Ophthalmol Vis Sci. 2016;57(8):3836-3843.

17. Fischinger I, Seiler TG, Schmidinger G, Seiler T. Pupil centroid shift: marketing tool or essential clinical parameter? Ophthalmologe. 2015; 112(8):661-664.

18. Labiris G, Giarmoukakis A, Patsiamanidi M, Papadopoulos Z, Kozobolis VP. Mini-monovision versus multifocal intraocular lens implantation. J Cataract Refract Surg. 2015;41(1):53-57.

19. Labiris G, Sideroudi H, Rousopoulos K, Kozobolis VP. Cohesive versus dispersive-cohesive ophthalmic viscosurgical device in torsional intelligent phaco. J Cataract Refract Surg. 2015;41(3):681-682.

20. AcrySof [product information] Fort Worth, TX: Alcon Laboratories, Inc.; 2015.

21. Lee S, Choi M, Xu Z, Zhao Z, Alexander E, Liu Y. Optical bench performance of a novel trifocal intraocular lens compared with a multifocal intraocular lens. Clin Ophthalmol. 2016;10:1031-1038.

22. Mataftsi A, Bourtoulamaiou A, Haidich AB, et al. Development and validation of the Greek version of the MNREAD acuity chart. Clin Exp Optom. 2013;96(1):25-31.

23. Goertz AD, Stewart WC, Burns WR, Stewart JA, Nelson LA. Review of the impact of presbyopia on quality of life in the developing and developed world. Acta Ophthalmol. 2014;92(6):497-500. 
24. Kohnen T, Hemkeppler E, Herzog M, et al. Visual outcomes after implantation of a segmental refractive multifocal intraocular lens following cataract surgery. Am J Ophthalmol. 2018;191:156-165.

25. Hütz WW, Eckhardt HB, Röhrig B, Grolmus R. Reading ability with 3 multifocal intraocular lens models. J Cataract Refract Surg. 2006; 32(12):2015-2021.

26. Gundersen KG, Potvin R. Trifocal intraocular lenses: a comparison of the visual performance and quality of vision provided by two different lens designs. Clin Ophthalmol. 2017;11:1081-1087.

27. Schmickler S, Bautista CP, Goes F, Shah S, Wolffsohn JS. Clinical evaluation of a multifocal aspheric diffractive intraocular lens. $\mathrm{Br} J$ Ophthalmol. 2013;97(12):1560-1564.

28. Xu R, Gil D, Dibas M, Hare W, Bradley A. The effect of light level and small pupils on presbyopic reading performance. Invest Ophthalmol Vis Sci. 2016;57(13):5656-5664.
29. Illuminating Engineering Society. The IES Lighting Handbook. Illuminating Engineering Society, 10th edition, New York; 2011.

30. Te Kulve M, Schlangen L, Schellen L, Souman JL, van Marken Lichtenbelt W. Correlated colour temperature of morning light influences alertness and body temperature. Physiol Behav. 2018;185:1-13.

31. Whittaker SG, Lovie-Kitchin J. Visual requirements for reading. Optom Vis Sci. 1993;70(1):54-65.

32. Cataract IOLs; AcrySof ${ }^{\circledR}$ IQ ReSTOR ${ }^{\circledR}$ Multifocal; IOLs AcrySof ${ }^{\circledR}$ IQ ReSTOR $^{\circledR}+2.5$ D IOL. Available from: https://www.myalcon.com/ products/surgical/acrysof-iq-restor-multifocal-iol/restor-25/specifications.shtml. Accessed July 31, 2018.
Clinical Ophthalmology

\section{Publish your work in this journal}

Clinical Ophthalmology is an international, peer-reviewed journal covering all subspecialties within ophthalmology. Key topics include: Optometry; Visual science; Pharmacology and drug therapy in eye diseases; Basic Sciences; Primary and Secondary eye care; Patient Safety and Quality of Care Improvements. This journal is indexed on

\section{Dovepress}

PubMed Central and CAS, and is the official journal of The Society of Clinical Ophthalmology (SCO). The manuscript management system is completely online and includes a very quick and fair peer-review system, which is all easy to use. Visit http://www.dovepress.com/ testimonials.php to read real quotes from published authors. 